\title{
Normalization of Psyche by Healthy Lifestyle of Various Groups of the Population
}

\author{
Evgeniy Bryndin ${ }^{1}$, Irina Bryndina ${ }^{2}$ \\ ${ }^{1}$ Research Centre "NATURE INFORMATIC", Technological Platform Future Medicine, Novosibirsk, Russia \\ ${ }^{2}$ Pediatric Faculty, Novosibirsk State Medical University, Novosibirsk, Russia
}

Email address:

bryndin@ngs.ru (E. Bryndin), iriska26@ngs.ru (I. Bryndina)

\section{To cite this article:}

Evgeniy Bryndin, Irina Bryndina. Normalization of Psyche by Healthy Lifestyle of Various Groups of the Population. American Journal of Applied Psychology. Vol. 6, No. 4, 2017, pp. 51-56. doi: 10.11648/j.ajap.20170604.11

Received: July 7, 2017; Accepted: July 20, 2017; Published: August 15, 2017

\begin{abstract}
In the conditions of the increasing information loads of consciousness of the person, stabilization of mental health of the population becomes a main objective. The World Health Organization considers that the state of health of the person for $75 \%$ his way of life and a power supply system, for $10 \%$ - heredity defines, another $10 \%$ - environmental conditions, and only for $5 \%$ of service of health care. Health of the person most of all depends on a way of life. The healthy lifestyle will provide to the person mental and physical health all life.
\end{abstract}

Keywords: Health Creative Outlook, Health Abilities, Skills Daily Savings Health, Healthy Lifestyle

\section{Introduction}

In medical community various approaches to a concept health were created: hygienic, adaptive, genetic, prenosological, safe, equilibrium, physiological, on health, viable, self-regulating, endoecological, resonant, spiritual, naturalistic and the combined approaches. We will consider spiritually - naturalistic approach to a concept health. Approach is based on processes of the nature and a spiritual entity of the person. Such approach allows to consider spiritual, cultural, social, natural and psychological aspects of a normalization of mentality a healthy lifestyle.

\section{Natural and Spiritual Aspects of Health}

In the middle of the last century professor of Technical University of Munich of Winfried Otto Schumann has established that Earth and its ionosphere form the huge resonator where waves of ultralow frequencies which without effort can repeatedly bend around Earth extend. Within 60 years after the numerous researches and rechecks the frequency of Earth of $8 \mathrm{~Hz}$ has been determined. Since then in science this frequency is called the frequency of a resonance of Schuman. Formation of standing waves in such resonator has been called Schuman's resonance subsequently.

Doctor Robert Becker, measuring brain waves during the sessions of remote influence has established that these waves coincide with Schuman's waves. Besides, waves of the right and left cerebral hemispheres at such moments, are equal on frequency and are opposite on amplitude that leads to formation of standing waves. Standing waves of a brain are capable to enter interaction with Schuman's waves. Doctor Robert Becker is convinced that the uniform vibration frequency capable to influence live surrounding objects including on water is the cornerstone of the universe. He has measured waves of a brain of many spiritual healthy people. He has found out that all of them have identical frequencies $8 \mathrm{~Hz}$, isn't dependent on their religious and spiritual traditions, and are synchronized with Schuman's waves both on frequency, and on a phase. Healthy people have balanced mentality and a resonance of cages in a biofield at a vibration frequency of 8 hertz.

Health of the person is a psychophysiological state with balanced mentality and functioning of an organism at an electromagnetic frequency of cages of 8 hertz and with a wavelength of 8 meters in the resonance mode in environmentally friendly internal and the environment.

In the USA (NASA) and Germany (M. Planck's institute) long experiments as a result of which it has been established that Schuman's waves are necessary for synchronization of 
biological rhythms and normal existence of all live on Earth were made. Today the electromagnetic background of the planet as a result of activity of the person has undergone essential changes and is polluted to such an extent that the organism doesn't hear Schuman's waves. For this reason of NASA uses generators of waves of Schuman for ensuring normal activity of personnel. Schuman's waves is a real vital factor.

In the 50th years of the 20th century it has been proved that intensity of a resonance of Schuman directly influences higher nervous activity of the person, and also his mental abilities. Thanks to a resonance of the waves of Schuman having a natural origin and standing waves of a brain, spiritual people for whom a cerebral hemisphere work in a synchronous rhythm have a healthy state. The science has confirmed it experimentally.

The medicine develops, and health of society worsens. It is more and more medicines; it is more and more surgical interventions; it is more and more hi-tech devices - and diseases advance medical medicine. We began to live longer, but quality of our life is worse, we feel worse. The medicine isn't guided by the spiritual principles and criteria of health therefore she doesn't fight for health, and is at war with diseases.

Human life has the spiritual nature which cornerstone spiritual processes are. Spiritual processes of activity of the person and society are closely connected. They will help to get and keep health to mankind on a global scale [1]. Spiritual infrastructure of society influences in global and defining way health of everyone. To restore and keep health, understanding of spiritual processes of health is necessary. It is necessary to study spiritual that you don't see, you don't feel, you don't realize. There is a global interrelation between spiritual processes of the person and his physical health. Spiritual quality, as well as physical, gives in to a training. From a spiritual state to a healthy state will be more rather. Interrelation between spiritual processes of the person and his physical health, and also a condition of all society, fundamental. Supports a healthy condition of the person spiritual mental energy which is generated by a spiritual thought way, an ethical image of the word, good wishes, a healthy image of activity in an ecological pure environment, spiritual bonds with society, love to a visible and invisible environment. Accumulating spiritual mental energy, the person increases also creative working capacity.

The person can be protected by spiritual mental energy from infectious diseases, be exempted from cancer, diabetes and other diseases that is confirmed with practice on the basis of spiritual knowledge. Spiritual knowledge is valid healthy life: "My son! Listen to my words, and to my speeches bend your ear; yes they don't depart from your eyes; store them in your heart: because they life for this purpose who has found them, and health for his all body (Parable 4:20-22)." Researchers have experimentally confirmed positive preventive influence of spiritual doctrines and processes on improvement of the person and all wildlife. Spiritual processes of difficult essence of the person and society are connected with natural processes of improvement. At the end of the last century the scientific world has been excited by results of experiments of the Japanese scientist Masaru Emoto, visually proved that water under the influence of our thoughts, emotions, words changes the structure. Masaru Emoto's experiments convincingly prove that the spiritual word makes healthy impact in a resonance with Schuman's wave.

\section{Tasks and Methods}

His transfer to a healthy lifestyle becomes the main task for ensuring mental health of the population. Mental processes are implemented by mental energy. Biogenous converters of mental energy of spiritual healthy life generate healthy psychophysical processes and a condition of the person.

In article the research of mental energy, its value in normalization of mentality of the person is conducted. Stages of transition to a healthy lifestyle and organizational actions for normalization of mentality are offered by comprehensive knowledge, individual development and improvement of a healthy lifestyle.

\section{Researches of Mental Energy}

Mental energy - the term, is offered by S. Freud for the description of specifics of movement of attention, interest and attachment from one object (or the current activity) on another. In Moore's - Faiyna's definition mental energy is the cornerstone of any activity of the psyche device and all psyche manifestations.

The main functions of mental energy are divided into two groups: motivational and tool. The first is expressed as accumulation of mental energy to maximum permissible value. Tool function serves for realization of various psyche mental processes and normalization of psyche of the person.

At the moment, the psychological science can't give the answer to a question of what specificity of mental energy. In psychological practice and the theory connection of mentality with a brain and an innervation of heart is established that doesn't facilitate understanding of the psychological mechanism of emergence of mental energy [1-4]. Storages of mental energy are soul, a brain and an innervation of heart. A biological conductor of mental energy is the cover of nervous fibers of the lipidic nature. Violation of a lipidic exchange reduces mental abilities. The thought of reason makes active a brain and soul on participation in formation of qualities of mental energy. Mental energy, a brain, soul and nervous system of an organism participate in realization of mental process. Active mental energy is a substance of interaction of subjects of the live world. Interaction of subjects of the live world is carried out by quality of energy of mental states: tranquility, aggression, love, etc. The thinking, desires, feelings generate qualitative conditions of mental energy. The musician accumulates cognitive sensual tool mental energy of melodies. And at any time and in any place can make 
active mental energy of melodies and listen to them in itself. The Russian young musician Yaroslav Timofeev, the participant of TV program "Surprising people" has such gift. Each person accumulates tool professional cognitive sensual mental energy: athlete motive, artist visual, researcher subject, etc.

The American scientist, the researcher Paul D. Mak Ling, has entered the term "limbic system" and has developed the concept of a triune brain of the person. The sense of this concept consists that the human brain consists of three parts: a so-called reptilian brain of instincts - the most ancient land vertebrate animals; limbic brain of motivational behavior (mammals) and neocortex (new bark) of the person. Each of these parts in one way or another participates in formation of tool mental energy, but differently, and generates her different types.

The reptilian brain is the oldest, from the evolutionary point of view. He realizes perceptual mentality. Through vegetative nervous system he regulates instinctive functions of life support. The reptilian brain develops the main instinctive action plans for primitive emotional processes, such as investigation, food, aggressive manifestations of domination, and sexuality. He bears responsibility for the main tendencies of instinctive action and a habit connected with primitive questions of a survival. Mental manifestations of a reptilian brain arose at astronauts. According to stories of the astronaut tester Sergey Krichevsky: the astronaut unexpectedly and quickly leaves habitual human shape feeling and turns into a dinosaur.

The limbic system of a brain realizes touch mentality. She develops behavioural and psychological decisions, such as suffering, collective attachments, playfulness, education of posterity, subjective feelings and emotional reactions to the events in the nature interacting with congenital motivational system. For realization of these actions it generates tool animal mental energy. The child's life till five years in pack of animals, the quality of active mental energy accumulated from them in a brain doesn't form language speech and cogitative activity.

Neocortex (new bark) is tied with consciousness, with thoughts. He realizes reflective mentality. The living position of the person, his belief, stereotypes, norms of morals, etc. is kept in this structure. The American researcher Jacques Panksepp describes bark function as processing of propositional information on the events in the world which are especially received by means of sight, hearing and touch. The developed new bark generates semantic tool mental cognitive (informative) energy for realization of communicative associative thinking. With his help we make plans for the future, we analyze, we are trained, communicate also other. She puts in action non-material, or ideal, mentality components. The thinking, memory, attention begin to work, representations, come to life the experiences and knowledge which are stored in cells of a brain, installations, values, requirements waken, once acquired habits, skills, abilities emerge in consciousness.

Places of manifestation of mental energy are the nervous ways activated in the course of brain activity. Mental clever energy, influencing through a wave genome the genetic mechanism, forms functioning of a brain in the course of creative activity.

Energy has allocated images, thoughts, requirements, abilities, emotions, feelings, knowledge, installations, moods, habits, desires, motives, properties of character, - all these and other manifestations of mentality are carriers ideal. The matter is that they are sated with information which is a component of mental energy. Information constantly works, is in process of transformation and that is extremely important, exists in very squeezed form. The brain of each person stores a huge number of information ready to declare oneself at any time. Information has filled our consciousness. It is necessary to watch purity of thoughts and all life. The person has to accumulate and show constantly mental energy communicative spiritually semantic values and actions. Important to the person to accumulate tool mental spiritual energy of manifestation of human qualities, moral energy of public behavior and energy of healthy activity.

Uniform accumulation, distribution and use of spiritual, moral and healthy mental energy and normalization of cognitive thinking and mentality are carried out by knowledge, development and improvement of a healthy lifestyle. Today, more than ever, the comprehensive knowledge, individual development and improvement of a healthy lifestyle at the spiritual, social and physiological level is necessary. A healthy lifestyle of people reaches and keeps a healthy state.

Instrumental mental energy of a healthy lifestyle via biogenous converters generates healthy psychophysical processes and a condition of the person.

\section{Transfer of the Population to a Healthy Lifestyle}

It is possible to transfer the population to a healthy lifestyle through the Centers of Health, sanatorium institutions, the educational organizations. Transition to a healthy lifestyle is carried out in four stages [5-19].

Stage 1. Formation of the clean internal environment. The pure internal environment is one of necessary conditions of a wave resonance of cages. The clean internal environment is formed by useful habits:

1. At the spiritual level: formation pure thoughts and desires.

2. Development of an ethical lexicon of communication.

3. At the power level communication with clean nature: absorption by enzymes of light energy, vibrations of flora, equilibration of mentality by tranquillity of the nature, an emotional positive spirit from beauty of the nature, air, solar and water physical exercises, inhalation of clean air, coordination of the internal environment of an organism with the natural.

Improvement of health in ecological pure environment develops nature needs and a habit to communicate with the 
nature. Nature need and habit to communicate with the nature normalize genetically internal environment of an organism through a wave genome.

4. Maintenance of the internal environment of an organism by release from negative energy: water procedures in soul or a bathroom before the use of food, and also once a week in a bath.

Desire of improvement of health after stay in the adverse power environment and to keep it develops nature need and a habit to take a shower or a bathtub before the use of food and once a week to clean an organism in a bath steam room.

Nature need and a habit to take a shower or a bathtub before the use of food and once a week to clean an organism in a steam room of a bath relieve an organism of negative energy and supports pure the internal environment of an organism.

5. Preservation of the pure internal environment classical, sacred, harmonious music at the genetics-wave level.

The desire to have and keep good health develops nature need and a habit to listen to harmonious music. Nature need and a habit to listen to harmonious music support genetically the pure internal environment of an organism through a wave genome at the power level.

6. Development of alkaline food $(80 \%$ of pure alkaline food and $20 \%$ of clean acid food) for normalization of acidbase balance of biological environments of an organism.

The desire to keep good health after acceptance of food develops nature need and a habit of alkaline food. Nature need and a habit of alkaline food by the rule to choose useful among tasty and tasty among the useful support acid-base balance of biological environments of an organism through a metabolism at the physiological level.

7. Normalization of acid-base balance through a water exchange at the physiological level by use the pure water.

Nature need and habit to use clear water support acid-base balance of biological environments of an organism through a cellular and intercellular water exchange.

8. Observance of hygiene for maintenance of the environmentally friendly internal environment of an organism.

Nature need and habit to observe hygiene support acidbase balance of biological environments of an organism clarification it from parasites and pollution.

9. Diagnostics of acid-base balance of biological environments of an organism.

Nature need and habit to diagnose acid-base balance of biological environments of an organism help to control it.

Stage 2. Development of improving abilities for achievement of a healthy state. Spiritual, mental and power purity are necessary conditions of a wave resonance of cages. The stage includes the following useful habits:

1. Spiritual actions, such as, reading spiritual literature, visit of spiritual actions, development of spiritual consciousness and spiritual and moral qualities, formation of spiritual bonds for achievement of a spiritual healthy state.

Development of abilities to make spiritual actions develops nature need and a habit to get rid from harmful passions, to gain a sound spirit and spiritual health.

2. Formation of just peace kind thoughts and desires for spiritual activity.

Nature need and habit to form just peace kind thoughts and desires conduct to spiritual activity and spiritual health.

3. Development of spiritual abilities of humility, forgiveness, mercy, formation of the peace kind relations in various social conditions and a family for spiritual activity.

Abilities of manifestation of humility, forgiveness, mercy, formation of the peace kind relations for equilibration of soul in various social conditions and a family develop nature need and a habit to be soul balanced and to have a sound spirit and spiritual health.

4. Manifestation of spiritual and moral qualities goodwills and blessings, mercy and justice for spiritual activity.

Manifestation of spiritual and moral qualities goodwill and blessings, mercy and justice develop nature need and a habit to build the peace kind relations and forms a sound spirit and spiritual health.

5. Development of abilities of control of vital systems of an organism and its complete normal functioning by physical exercises: charging of a power system, physical culture of a tone of an organism and gymnastics of rhythms for achievement of a physical healthy state of an organism.

Ability of control of vital systems of an organism and its complete normal functioning develop needs of nature and a habit to support a healthy state of an organism.

6 . The healthy food for maintenance of a physical healthy state of an organism.

Healthy food improves a healthy habit to support a physical healthy state of an organism.

7. Development of complex abilities of achievement of a healthy state on the basis of system of cellular selfrestoration of an organism improvement of a qualitative condition of cages at the spiritual, power, physiological and anatomic levels.

Ability of improvement of a qualitative condition of cages at the spiritual, power, physiological and anatomic levels on the basis of system of cellular self-restoration of an organism improves a healthy habit to support a complete healthy state of an organism.

8. Frequency and resonant diagnostics of a healthy state.

Development of a habit periodically to diagnose an organism helps to support a healthy state.

Stage 3. Acquisition of skills health of saving for preservation of a healthy state. It includes the following useful habits:

1. Development of rules of daily preservation of a healthy state.

Development of rules develops skills and a daily habit to keep a healthy state.

2. Equilibration of soul in social conditions by peace kind relations, doing good, evading it is evil, looking for the peace and aspiring to it for spiritual health of saving.

Abilities and skills of manifestation of humility, forgiveness, mercy and the peace kind relations 
counterbalance soul in various social conditions and develop a daily habit to be soul balanced to have a sound pirit and to support a spiritual healthy state.

3. Daily formation of physical healthy functioning of an organism at the beginning of day control of vital systems.

Skills of ensuring healthy functioning of an organism develop a daily habit of preservation of a healthy state.

4. Coordination with a daily natural cycle of activity in social, natural and house conditions for preservation of complete healthy functioning of an organism.

Skills of daily coordination of healthy activity with a daily natural cycle develop a daily habit of preservation of a healthy state in various social, natural and house conditions.

5. Complex daily preservation of a healthy state at the spiritual, power, physiological and anatomic levels in various house, natural and social conditions on the basis of system of cellular self-restoration.

Skills of complex daily preservation of a healthy state at the spiritual, power, physiological and anatomic levels in various house, natural and social conditions on the basis of system of cellular self-restoration develop a habit of preservation of a complete healthy state during every day.

6. Preservation of physical healthy functioning of an organism healthy food.

Skills of daily healthy food constantly support a healthy state.

7. Frequency and resonant diagnostics of a healthy state.

Weekly diagnoses an organism helps support a health.

Stage 4. Accumulation of experience of a healthy lifestyle for preservation of a healthy state within a year. Accumulation of experience is carried out by skills health of saving in various house, social and natural seasonal conditions (in the spring, in the summer, in the fall and in the winter). Experience includes the following useful habits:

1. Seasonal preservation of balanced soul and ensuring complete healthy functioning of an organism in the summer, in the fall, in the winter, in the spring on the basis of system of cellular self-restoration.

Experience of seasonal preservation of balanced soul and ensuring complete healthy functioning of an organism in the summer, in the fall, in the winter, in the spring on the basis of skills of daily preservation of a healthy state develops nature need and a habit to support a healthy state of an organism within a year.

2. Healthy seasonal food.

Accumulation of experience of seasonal healthy food develops nature need and a habit to support a healthy state of an organism within a year.

3. Choice of seasonal natural clothes.

Accumulation of experience of a choice of seasonal natural clothes develops nature need and a habit to support a healthy condition of an organism within a year.

4. Accumulation of experience of complex coordination of social healthy activity with an annual natural cycle at the spiritual, power, physiological and anatomic levels in various house, natural and social conditions.

Accumulation of seasonal experience of complex coordination of social healthy activity with an annual natural cycle develops nature need and a habit to support a healthy condition of an organism within a year.

5. Accumulation of experience of formation of family tradition of a healthy lifestyle.

Accumulation of experience of formation of family tradition of a healthy lifestyle develops nature need and a habit to support a healthy condition of an organism within a year family members.

6. Accumulation of experience of periodic frequency and resonant diagnostics of a healthy state.

Experience accumulation periodically to diagnose an organism helps to support a healthy state within a year.

7. Accumulation of experience of formation of cultural public tradition of a healthy lifestyle.

Accumulation of experience of formation of cultural public tradition of a healthy lifestyle develops nature need and a habit to motivate citizens, to reach and support a healthy condition of an organism and to lead a healthy lifestyle within a year.

\section{Result}

For training of the population in a healthy lifestyle by the Novosibirsk research center "ESTESTVOINFORMATIKA" scientific and practical and scientific and methodical literature on a healthy lifestyle is offered.

1. Lecturers for society KNOWLEDGE of formation health of creative outlook and motivation to healthy lifestyle the population.

2. Pedagogical workers for chairs of Health of universities and for schools on formation health of creative outlook and motivation to healthy lifestyle at the younger generation.

3 . Health workers for the centers of health and sanatorium establishments for carrying out consultations, a practical training on transition to a healthy lifestyle and diagnostics of a state.

4. Social workers for carrying out a practical training with the population on transition to healthy lifestyle and formation of family and cultural public tradition of a healthy lifestyle.

5. Games-masters for training of the younger generation in control of vital systems and complete normal functioning of an organism.

The project in 2012 was included into library of the best Russian experiment on a healthy lifestyle. What is confirmed with the certificate from the Ministry of Health of the Russian Federation.

\section{Conclusion}

When the person leads a healthy lifestyle, it is updated by spirit of mind and clothes in the spiritual person with normal mentality. The spiritual person lives under the law of love, without doing anybody the harm.

Healthy lifestyle of people normalizes mentality, develops and shows creative and professional abilities.

The accumulated tool mental energy of a healthy lifestyle 
of the population normalizes mentality of people, forms public culture of healthy activity and peace psychological climate of society.

Normalization of mental cognitive and communicative processes of citizens of various age and social groups knowledge, development and improvement of a healthy lifestyle accumulates positive creative mental energy.

\section{References}

[1] Vekker L. M. Mentality and reality: uniform theory of mental processes. - M.: Sense. 2000. 685 pages.

[2] V. I. Vernadsky. Biosphere and noosphere. M: AYRES - THE PRESS. 2004. 385 pages

[3] Boris Burdykin. Space secret of water. 2007. 285 pages.

[4] Bekhtereva N. Magiya of a brain and life labyrinths. - M.: ACT; SPb.: Owl, 2007. - 349 p.

[5] Bryndin E. G. Ecological Drug-Free Health Care. International Multidisciplinary Congress "Progress in Fundamental and Applied Sciences for Human Health". Sudak, 2004, pp. $81-82$.

[6] Bryndin E. G., Bryndina I. E. Healthy Man and Society Bases. Tomsk, TPU, 2011, 302 p.

[7] Bryndin E. G., Bryndina I. E. Healthy Longevity Bases. Germany, LAP Lambert Academic Publishing, 2012, 225 p.

[8] Bryndin E. G., Bryndina I. E. Healthy Life Style Syllabus for School Children. II All-Russian Scientific and Practical Conference "Creation of the Integrated Educational Space for Children's Endowments Development: Kindergarten - School - University", Part I, Pedagogy of Endowments. Tomsk: TNTI, 2012, pp. $182-187$.

[9] Bryndin E. G., Bryndina I. E. Students Health Indicator Dynamics Increase Monitoring. International Conference "Modern Aspects of Federal State Learning Standard and Federal State Requirements Realization”. Krasnoyarsk: Kras GMU, 2013, pp. $500-504$.
[10] Bryndin E. G., Bryndina I. E. How to Pass to the Healthy Life Style. Tomsk: TPU, 2013, 288 p.

[11] Bryndin E. G., Bryndina I. E. Social Infrastructure of Forming Population's Healthy Life Style Management. International Scientific Symposium "Society and Continuous Prosperity of a Man”. Tomsk: TPU, 2014, pp. $102-106$.

[12] Bryndin E. G., Bryndina I. E. Formation of Worldview of Healthy Lifestyle at Young Generation. $2^{\text {nd }}$ All-Russian Medical Scientific Practical Conference "Development of Russian Health Protection at the Present Stage". Moscow: Editus, 2014, pp. 177 - 183.

[13] Evgeny Bryndin. Uniform economy of global wellbeing. Germany: LAP LAMBERT Academic Publishing. 2015. 105 c.

[14] E. G. Bryndin \& I. E. Bryndina. Natural-Science Aspects of Health. / Weber Medicine \& Clinical Case Reports. Vol. 1 (1). 2015. pp. 134-137. URL: http://weberpub.org/wmccr/wmccr_122.pdf

[15] Е. Г. Брындин. Formation of the healthy person, family and society. Germany: LAMBERT Academic Publishing. 2015. 93 c.

[16] Е. Г. Брындин. Spiritual and scientific bases of health. Germany: LAMBERT Academic Publishing. 2016. 120 c.

[17] Bryndin E. G., Bryndina I. E. Healthy Wellbeing of the Person and Society. Journal "The European Proceedings of Social \& Behavioural Sciences Ep SBS”. Volume XIX. 2017. Pages 130-139. URL: http://dx.doi.org/10.15405/epsbs.2017.01.17.

[18] E. G. Bryndin, I. E. Bryndina. Sanatorium Rehabilitation of the Population by the Healthy Lifestyle. International academic journal "Rehabilitation Sciences", Volume 2, Issue 2. Science Publishing Group, USA. 2017. P. 35-40. URL: http://www.sciencepublishinggroup.com/journal/archive.aspx? journalid $=234 \&$ issueid $=-1$

[19] Evgeniy Bryndin, Irina Bryndina. Formation of Public Health Care on Basis of Healthy Lifestyle. International Journal of Psychological and Brain Sciences. Vol. 2, No. 3, 2017, pp. 6368 . 